NBER WORKING PAPER SERIES

PITEALTS IN THE CONSTRUCTION AND USE

OF EFFECTIVE 'TAX RATES

David F. Bradford

Don Fullerton

Working Paper No. 688

\author{
NATIONAL BUREAU OF ECONOMIC RESEARCH \\ 1050 Massachusetts Avenue \\ Cambridge MA 02138 \\ June 1981
}

The authors are grateful to the NSF, NBER, and Princeton University for financial assistance, and to Thomas Kronmiller for research assistance. For general discussions on these issues, we are grateful to Robert E. Hall, Dale W. Jorienson, and Mervyn A. Kine. The research reported here is part of the NBE' $s$ research program in Taxation and project in Capital Formation. Any opinions expressed are those of the authors and not those of the National Bureau of Economic Research. 


\title{
PITFALLS IN THE CONSTRUCTION AND USE \\ OF EFFECTIVE TAX RATES
}

\begin{abstract}
A cost of capital formula can be a useful tool in estimating the effective tax rate on a dollar of marginal investment in a particular industry. There are a number of procedural issues, however, which can greatly affect the resulting estimates. First, tax rate estimates vary with the interest rate used in the formula. Second, the nonlinearity of tax rate formulas may lead to anomalous results. For example, an investment that is actually subsidized may appear to bear a positive tax. Or, tax rates may become arbitrarily large when the project's rate of return approaches zero. Third, effective tax rate results depend on the assumed relationship between inflation and nominal interest rates. Our conclusion is that much sensitivity analysis and specificity are required in studies that undertake to estimate effective tax rates.
\end{abstract}

David F. Bradford

Don Fullerton

Woodrow Wilson School of Public and International Affairs

Princeton University

Princeton, NJ 08544

(609) 452-4811 


\section{PITFALLS IN THE CONSTRUCTION AND USE \\ OF EFFECTIVE TAX RATES}

David F. Bradford

Don Fullerton

\section{Introduction}

The easiest and most common approach to estimating effective tax rates on investment has been to calculate actual taxes paid as a proportion of capital income. This "flow of funds" approach is particularly useful for income effects to capital owners, revenue effects to government, or generally for discussing the relative size of the public sector. Some have also used this approach to capture the different incentive effects for using capital in different industries. The implicit assumption is that marginal tax rates in a given industry are not far from the ratio of actual taxes to capital income in that industry. Harberger (1966) estimated the efficiency cost of differential capital income taxation using this approach, as did Shoven in his (1976) correction to Harberger. The approach is still used in recent general equilibrium estimates by Fullerton, King, Shoven, and Whalley (1981).

A new approach is now emerging, based on the pioneering work of Hall and Jorgenson (1967). Their cost of capital formulas have long been used to analyze investment and the incentive effects of tax policy changes. More recently, the formulas have been used to estimate effective marginal tax rates, as in Hall (1981) and Jorgenson and Sullivan (J-S, 1981). Tax rates based on the cost of capital approach have been used to recalculate Harbergertype efficiency costs, as in Gravelle (1981), and to recompute general equilibrium effects, as in Fullerton and Gordon (1981). 
This newer approach considers a "hypothetical project" of a dollar invested in a particular asset to be used in a particular industry. (Some versions of the approach also assume that the investment is maintained in real or nominal terms jy subsequent reinvestment.) The view of taxes is prospective in the sense that the cost of capital formula looks at the expected change in future tax liabilities, usually discounted to the time that the original investment takes place. The method can simultaneously incorporate actual depreciation rates, type of finance, eligibility for investment tax credit, accelerated depreciation rules, and depreciation at historical cost. It is greatly facilitated by the availability of estimates for depreciation rates of different assets, such as those in Hulten and Wycoff (1981).

The prospective nature of the cost of capital (hypothetical project) approach implies that it is probably more useful for investigating incentive effects. It measures the expected tax consequences if a given investment is undertaken. It also concentrates on marginal effects by considering a particular unit of investment. Though we see many potential benefits of using this approach, the purpose of this paper is to investigate some of its dangers. In particular, we shall illustrate three points that should be considered by any study which uses the cost of capital approach.

First, as mentioned above, the cost of capital method considers the expected future tax liabilities associated with a hypothetical project, discounted to the time that the original investment takes place. Though the investment tax credit has immediate consequences, other features of tax systems do not. Accelerated depreciation, for example, has the effect of delaying some tax liability. As a result, effective tax rate estimates 
will necessarily depend upon the after-tax interest rate or other rate used for discounting. We shall show this sensitivity below by plotting a tax rate estimate against the interest rate used to obtain it.

Second, the tax law allows some assets to be depreciated at rates faster than their values decline. With investment tax credits and with the deductibility of nominal interest payments, the asset need not earn a positive marginal product for the investor to receive a normal return. Though the Implied subsidy might be measured in a meaningful way, the rate of subsidy might not be. When the investment's return in the denominator of an effective tax rate formula approaches zero, the rate of subsidy can be arbitrarily high. Similarly, on an asset with a low real return, a positive tax can be an arbitrarily high portion of it. This problem can be dealt with by using the numerators of these tax rate estimates alone to describe the effective tax wedge on a particular asset in a particular industry.

Third, effective tax rate estimates depend on assumptions about how inflation affects nominal interest rates. Hall (1981) and J-S (1981) effectively assume that nominal interest rates increase by the inflation rate over one minus the corporate tax rate. This increase is just enough to keep the real after-tax interest rate constant for corporations. If all taxpayers faced the same tax rate as corporations, and if the rules for measuring the income from real investments were perfectly indexed for inflation, then a strong a priori case could be made for this behavior of interest rates. The real consequences of given decisions to borrow, lend, and invest would then be independent of inflation rates. However, historical cost depreciation, nonuniform tax rates, and other tax features tend to 
weaken this a priori case. Indeed, Feldstein (1980) has argued that the monetary authorities have acted so as to impose Fisher's Law, keeping the real before-tax interest rate invariant with respect to inflation. We show below how tax rate estimates differ according to whether nominal interest rates increase by just the rate of inflation, or by enough to keep real after-tax rates constant.

This paper does not seek to estimate new or better effective tax rates. It only seeks to investigate the sensitivity of existing estimates to some of the issues just described. These can be clarified adequately within the context of fairly simple and straightforward cost of capital formulas such as those used by Hall (1981) and J-S (1981). In order to be particularly careful about the assumptions used in this procedure, we rederive the cost of capital in Section II.1. In order to be particularly careful about what is being estimated, we describe an array of possible tax rate definitions in Section II.2. Then in Section II.3, we state the parameters of the investment and tax systems, chosen for comparability with Hall (1981). We also display the possible outcomes for savers and investment returns. These constitute the components of effective tax rates.

In the three parts of Section III, we elaborate on each of the three issues raised above. Tax rate estimates are shown to be sensitive to the interest rate in Section III.1. The fact that tax rate definitions are very nonlinear relationships is illustrated in Section III.2. The effect of inflation on nominal interest rates also significantly affects the estimates, as shown in Section III.3. It should be clear by the end of this paper that the sensitivity of tax rate estimates implies that one can obtain a wide variety of tax rate estimates with different choices of parameter values and other assumptions. 
The problems emphasized in this paper involve primarily mechanical features of the analysis. That is, they concern potential misunderstanding of the tax rate formulas and of the assumptions often encountered. We also touch on some underlying modelling problems through the course of the paper. Foremost among these is the question of the true relationship between inflation and the interest rate. There are, however, several additional aspects of the use of effective tax rate estimates which deserve attention. In the concluding remarks of Section IV, we allude to further work we are doing on these problems.

\section{Analytical Framework}

Because we feel that previous studies have not been explicit enough about what they were estimating, we devote considerable attention at the outset to deriving and defining different sorts of tax rates. Any of these might be estimated by a particular study.

\section{1. The Cost of Capital}

We begin with a simple expression for the cost of capital, that is, the annual market rental price of a unit of capital, predicted to obtain in a competitive market equilibrium. Although a simflar derivation has been exposited many times, it will be helpful to have a restatement of the underlying assumptions and the interpretations of different variables.

Define $\rho$ to be the expected real rate of return to the hypothetical project, net of economic deprectation at the exponential rate $\delta . \underline{1 /}$ In light of our introductory comments, we require a model incorporating the dependence of $\rho$ on the nominal interest rate 1 and on the rate of inflation $\pi$. However, many complexities can be safely ignored. Hall (1981), for example, considers (but does not really use) the possibility that a proportion of accrued capital gains are taxable at the statutory corporate tax rate u. 
J-S (1981), on the other hand, allow for (but then abstract from) the possibility that the acquisition cost $q$ and the rental price $c$ of the asset are arbitrary functions of time, rather than assuming only that they increase with inflation. J-S also consider the possibility that the rate of economic depreciation is an arbitrary function of time, rather than using our simpler assumption that true depreciation is at constant exponential rate $\delta$. They allow depreciation deductions as an arbitrary function of time, while we assume the tax law allows depreciation deductions on a historical cost basis at constant exponential rate $\delta^{\prime}$.

An investment tax credit at rate $k$ completes the description of our hypothetical real investment profect and its tax consequences. A corporate purchaser of a unit of real capital incurs an immediate after-tax-credit expense of $(1-k) q$, and subsequently obtains a cash inflow, expressed as a function of $\tau$, the time since acquisition of the asset. This cash inflow includes rental at a rate that starts at $c$ and grows at the rate of inflation $\pi$. The quantity of capital embodied in the investment declines at the depreciation rate $\delta$. At time $\tau$ the rental receipts thus equal $(1-u) c e^{(\pi-\delta) \tau}$ after the corporate income tax. The cash inflow also includes tax reductions due to depreciation allowances, which at time $\tau$ equal uqq $\delta^{-\delta^{\prime} \tau}$ (depreciation at rate $\delta^{\prime}$ is allowed on the remaining basis $\left.q e^{-\delta^{\prime} \tau}\right) . \underline{2}$ By changing $k, u$ and $\delta^{\prime}$, the tax authorities change the attractiveness of these net-of-tax cash flows, given $q, c$ and $\pi$. Since (at least) $q$ and $c$ are endogenous to the system, changes in the tax rules will ultimately be reflected in changes in the values of $q$, $c$, or both.

The power of the analysis is based upon the valuation of such cash flows. More specifically, it is based on valuation relative to avaflable alternatives. 
Prominent among these alternatives is the purchase or sale of debt. The analogue of buying a machine is buying debt, or lending. If the market interest rate $i$ is constant, for an intial outlay of $\$ 1$, a corporation can accummulate $e^{(1-u) i \tau}$ dollars by time $\tau$, where the factor $(1-u)$ in the exponent reflects the taxation of interest receipts. Of course, most nonfinancial corporations are sellers of debt, not buyers. The emphasis therefore is usually on the deduction of interest outlays and not the taxation of interest receipts. Note that this deduction is a logical extension of the taxation of interest receipts. It is not, as sometimes made to appear, an explicit subsidy of corporate borrowing.

If borrowing and lending are unconstrained, and if real investment is riskless, it is possible for a corporation to undertake offsetting transactions, by selling debt and buying an equal amount of real capital. Explicitly or implicitly, most analyses depend upon the elimination of any possible pure surpluses from such transactions to determine the equilibrium relationship among $i, q$, and $c$ (given $\pi$ and the tax rules). More prosaically, most analyses represent the corporation as discounting nominal cash flows at the "after tax nominal interest rate," (1-u)i.

In equilibrium, then, the present value of the nominal cash flow from a unit of capital, as summarized above, must just equal the initial outlay. This implies

$$
(1-k) q=\int_{0}^{\infty}(1-u) c e^{(\pi-\delta) \tau} e^{-(1-u) i \tau} d \tau+\int_{0}^{\infty} u q \delta^{\prime} e^{-\delta^{\prime} \tau} e^{-(1-u) i \tau} d \tau .
$$

Explicit integration leads to a relatively simple relationship between the 
gross of depreciation rental rate, $c / q$, and the interest and inflation rates:

$$
\frac{c}{q}=\frac{\delta+(1-u) i-\pi}{1-u}\left[1-k-\frac{u \delta^{\prime}}{\delta^{\prime}+(1-u) i}\right]
$$

This is our basic equation for later computations. Note that this equilibrium condition is independent of the actual financing method of the corporation; it does not matter whether the source of the investment funds is debt or equity. The option of arbitrage between debt and real capital implies equation (2). $\underline{3}$ /

Since the original hall and Jorgenson treatment of this subject (1967), the notation $z$ has been the conventional symbol for the discounted sum of depreciation deductions on a one dollar investment. Therefore (2) can also be written as

$$
\frac{c}{q}=\frac{\delta+(1-u) i-\pi}{1-u}(1-k-u z),
$$

where it must be remembered that $z$ depends upon $i$ and $u$.

For changes in the tax parameters $u, k$, and $\delta^{\prime}$, it is conceptually straightforward to calculate the effect on the equilibrium social rate of return, $\rho$, which equals $c / q-\delta$. This can be done for different combinations of $i$ and $\pi$. Commonly, though, a further simplification is adopted, namely, an assumed relationship between $i$ and $\pi$. This reduces the number of cases to consider, for the whole system described by (2) then has a single exogenous parameter, $\pi .4 /$ While a number of relationships are 
possible, two particular assumptions about inflation and the nominal interest rate are often encountered. The first is a strict version of Fisher's Law. If we let $i_{0}$ represent the interest rate presumed to prevail in the absence of inflation, Strict Fisher's Law says that

$$
i=1_{0}+\pi
$$

The argument for this result is simply that this adjustment leaves all real borrowing and lending opportunities independent of the rate of inflation. Implicit is the absence of taxes on interest. With a tax at a flat rate $u$ on net interest receipts (which implies a deduction for interest payments), the same argument predicts what might be called Modified Fisher's Law:

$$
i=i_{0}+\frac{\pi}{1-u}
$$

Theory does not give us firm predictions about the relationship between $i$ and $\pi$ in a world of imperfect income measurement rules, diverse marginal tax rates, nonlinearities, noise, and other considerations. Feldstein and Summers (1978) estimate that $i$ has varied slightly less than point for point with $\pi$ in the U. S. since World War II. On the other hand, Hall (1981) explicitly assumes Modified Fisher's Law. J-S (1981) postulate constancy of the real rate of return on investment after the corporate tax, citing empirical work by Fraumeni and Jorgenson (1981). This procedure is equivalent to assuming Modified Fisher's Law when arbitrage with corporate bonds is encompassed by the model. $6 /$ 
Later we consider the choice between (4a) and (4b). For our illustrative calculations, we consider three situations: no inflation, 10 percent inflation with equation ( $4 a)$, and 10 percent inflation with equation ( $4 b)$. The real interest rate to a bondholder with no tax is the same in the first two scenarios, but the real interest rate after tax at rate $u$ differs. In the first and third scenarios, the real after corporate tax interest rate (1-u)i-T is the same, but the real interest rate for a non-profit (nontaxable) institution differs. There is no real interest rate which is the same in all three cases, and so we studiously avold defining any parameter as the real after-tax interest rate. Instead, we take as a basis of comparison the interest rate $i_{0}$ that would prevail with no inflation.

\section{II.2. Effective Tax Rates}

The concept of an effective tax rate on capital refers to some measure of the difference between $p$, the real social rate of return earned on a real asset, and $s$, defined as the rate of return received by the person or institution financing its purchase. Then we can define the tax "wedge," $t^{w}$, as

$$
t^{w}=\rho-s
$$

This wedge can be thought of as an annual levy on the spectfied financer with respect to a dollar's worth of the asset in question. It may be either positive or negative.

It is usual to express $t^{W}$ as a ratio to efther the social return or the saver's return. The first is a tax rate on a base that includes the tax: a "tax inclusive" rate in the language of the Meade Report (1978). Since the 
base is gross-of-tax, we refer to it as a "gross tax rate" $t^{g}$. The other tax rate is on a "tax exclusive" or net-of-tax basis, and is referred to here as a "net tax rate," $t^{n}$. These rates are related to $\rho$ and $s$ by

$$
\begin{aligned}
& t^{g}=\frac{\rho-s}{\rho}, \\
& t^{n}=\frac{\rho-s}{s} .
\end{aligned}
$$

Notice that these rates are nonlinear functions of $s$ and $\rho$, and may behave rather erratically in some circumstances. Particular care must be used where the denominator of one of these formulas approaches zero, or passes from positive to negative. In later sections we shall see examples of the practical relevance of this erratic behavior.

Different values of $\rho$ and $s$ can be derived for

(a) assets with different depreciation rates $\delta$,

(b) assets with different tax rules ( $\delta^{\prime}$ and $k$ ),

(c) savers with different tax circumstances (u, m),

(d) different types of finance (bonds, stock, direct ownership), and

(e) different $i$ and $\pi$ combinations.

In particular,we shall focus on an "effective corporate tax rate", a "total effective rate of tax on bond financed corporate investment", and a "total effective rate of tax on equity financed investment."

In performing this analysis however, there is some question as to what should be taken as constant. Since the interest rate $i$ is a price established on a market in which all can trade, it is arguably the natural fixed 
point. Given this interest rate and a single tax rate $u$ for all traders, the social return $\rho$ would be determined by the equilibrium condition (2) for arbitrage between bonds and real capital. In concluding remarks we touch upon the possibility of corporate and noncorporate arbitragers with different tax rates. For now, however, we make the customary assumption that the market is dominated by corporations with tax rate $u$. Because the corporation arbitrages between real capital and bonds yielding (1-u)i- $\pi$, it is either a borrower or lender at that real after-tax interest rate. In this sense, we can take $(1-u) i-\pi$ as the net return to savings of the corporation, ${ }^{3} \mathbf{c}^{*}$

Thus, the corporate tax wedge, the effective gross rate, and the effective net rate are given by

$$
\begin{aligned}
& t_{c}^{w}=\rho-s_{c}=\rho-[(1-u) i-\pi], \\
& t_{c}^{g}=\frac{\rho-s_{c}}{\rho}=\frac{\rho-[(1-u) i-\pi]}{\rho}, \\
& t_{c}^{n}=\frac{\rho-s}{{ }_{c}}=\frac{\rho-[(1-u) i-\pi]}{(1-u) i-\pi},
\end{aligned}
$$

Note that the model developed in the previous section implies $\rho$ and $i$ are functionally related to each other, and $i$ is functionally related to $\pi$. Hence the model implies values for the corporate tax wedge and the corporate effective tax rates as functions of $\pi$.

If we Imagine a corporation choosing to purchase a dollar's worth of real assets with some funds it has in the bank, the net of tax real return must be (1-u)i-n; otherwise (2) would not be satisfied. This can be thought 
of as income to the stockholders, who are taxed on it at marginal rate $\mathrm{m}_{\mathrm{e}}$. This personal rate is designed to capture the effective personal tax on these earnings when part may be paid as dividends and part retained. It should also account for the low effective personal rate on accrued capital gains resulting from retentions. The net return to stockholders on equity is thus $s_{e}=\left(1-m_{e}\right)[(1-u) i-\pi]$. The tax wedge on equity, the effective gross rate, and the effective net rate are given by

$$
\begin{aligned}
& t_{e}^{w}=\rho-s_{e}=\rho-\left(1-m_{e}\right)[(1-u) i-\pi], \\
& t_{e}^{g}=\frac{\rho-s_{e}}{\rho}=\frac{\rho-\left(1-m_{e}\right)[(1-u) i-\pi]}{\rho}, \\
& t_{e}^{n}=\frac{\rho-s_{e}}{s_{e}}=\frac{\rho-\left(1-m_{e}\right)[(1-u) i-\pi]}{\left(1-m_{e}\right)[(1-u) i-\pi]},
\end{aligned}
$$

An individual debtholder with marginal tax rate $m_{d}$ receives a real return on bonds of $\left(1-m_{d}\right) i-\pi$ after taxes. Call this return $s_{d} \underline{7 /}$ We are entitled to compare $s_{d}$ to the social return on corporate investment, and the difference is customarily referred to as the effective tax on corporate investment financed by debt. Thus the tax wedge on debt, the effective gross rate, and the effective net rate are given by

$$
\begin{aligned}
& t_{d}^{w}=\rho-s_{d}=\rho-\left[\left(1-m_{d}\right) i-\pi\right], \\
& t_{d}^{g}=\frac{\rho-s_{d}}{\rho}=\frac{\rho-\left[\left(1-m_{d}\right) i-\pi\right]}{\rho}, \\
& t_{d}^{n}=\frac{\rho-s_{d}}{s_{d}}=\frac{\rho-\left[\left(1-m_{d}\right) i-\pi\right]}{\left[\left(1-m_{d}\right) i-\pi\right]},
\end{aligned}
$$


In two senses, these effective tax rates have nothing to do with whether the investment is actually financed by issue of debt. First, because $i$ is a market interest rate, any debtholder with tax rate $m_{d}$ will earn $s_{d}$. The corporation earns $\rho$ on a particular investment. The values $\rho$ and $s_{d}$ are all that is required to define the effective tax rates, independently of any connection between the two. Second, when the corporation makes its real investment decisions by comparing the returns on capital and debt, there is a connection between $\rho$ and $i$. This relationship depends on potential and not actual arbitrage, however. Thus the $t_{d}$ expressions are not only defined, but relevant for analysis regardless of whether debt finance is actually used.

Two points may be noted from these formulas before we proceed to illustrate them. First,if the personal rate $\mathrm{m}_{\mathrm{d}}$ happens to equal the corporate rate $u$, then the total tax on debt (equation 10) is equivalent to the corporate rate alone (equation 8 ). When Hall or J-S report effective corporate tax rates $t_{c}^{g}$, we can reinterpret them as total tax rates $t_{d}^{\mathbf{g}}$ on a debt financed investment where the lender has a tax rate $m_{d}$ equal to $u$.

$$
\begin{aligned}
& \text { Second, if } m_{d} \text { is zero, then equation (10) implies } \\
& \qquad t_{d}^{g}=\frac{p-(i-\pi)}{\rho}=\frac{(c / q-\delta)-(i-\pi)}{(c / q-\delta)} .
\end{aligned}
$$

If we use equations (2) and (4b) to obtain $\rho$, this is exactly the tax rate on debt calculated by Hall (1981). Thus Hall's tax rates on debt can be thought of as the lowest extremes of a spectrum from $m_{d}=0$ to $m_{d}=u$. For the other extreme, we can simply look at the effective corporate tax rate $t_{c}^{g}$. Below, we reproduce Hall's results and then recalculate them for dif- 
ferent real net of tax interest rates and for different assumptions about how inflation affects nominal interest rates.

The various effective tax rate expressions are drawn together and summarized in Table 1.

\section{3. Parameter Values}

Having specified the mechanisms determining the social rate of return and the saver's rate of return, we can explore the behavior of the various effective tax rates under different assumptions about parameters. Hall (1981) has chosen a particular classification of investment types and saver types; it will facilitate our discussion to adopt the same parameter values. First, take $u$ to be .46 , the marginal tax rate for corporations where nearly all corporate investment takes place. For $\mathrm{m}_{\mathrm{d}}$, Hall uses a value of zero, on the assumption that all bonds are held by tax-exempt institutions. As we have mentioned, we can also consider the case of $m_{d}=u=.46$ with no extra calculations or table space. Thirdly, let me equal .28 , the value chosen by Hall. He assumes that the typical stockholder is in the 40 percent bracket, receiving one-half of corporate equity income as fully taxable dividends and the other half as capital gains. Only 40 percent of the latter are included in the individual income tax base. We regard the figure of .28 as somewhat high. The value of deferral and of the write-up of capital gains basis at death probably cut the effective proportion of accrued gains included in taxable income to something like 20 percent. 8 ' With this assumption, $\mathrm{m}_{\mathrm{e}}$ would be .24 . For purposes of illustrating the characteristics of the tax system, however, the difference is not of much importance.

Hall identifies three real assets. "Equipment" depreciates at 10 per- 
TABLE 1

Definition of Different Effective Tax Rates

Superscripts

\begin{tabular}{|c|c|c|c|}
\hline Subscripts & $\begin{array}{c}\mathrm{w} \\
\text { wedge }\end{array}$ & $\begin{array}{c}\mathrm{g} \\
\text { gross } \\
\end{array}$ & $\begin{array}{c}\mathbf{n} \\
\text { net }\end{array}$ \\
\hline $\begin{array}{c}c \\
\text { corporate }\end{array}$ & $t_{c}^{W}=\rho-s_{c}$ & $t_{c}^{g}=\frac{\rho-s_{c}}{\rho}$ & $t_{c}^{n}=\frac{\rho-s_{c}}{s_{c}}$ \\
\hline $\begin{array}{c}\text { e } \\
\text { equity }\end{array}$ & $t_{e}^{w}=\rho-s_{e}$ & $t_{e}^{g}=\frac{\rho-s_{e}}{\rho}$ & $t_{e}^{n}=\frac{\rho-s_{e}}{s_{e}}$ \\
\hline $\begin{array}{c}d \\
\text { debt }\end{array}$ & $t_{d}^{w}=\rho-s_{d}$ & $t_{d}^{g}=\frac{\rho-s_{d}}{\rho}$ & $t_{d}^{n}=\frac{\rho-s_{d}}{s_{d}}$ \\
\hline
\end{tabular}

where

$$
\begin{aligned}
& s_{c}=(1-u) i-\pi \\
& s_{e}=\left(1-m_{e}\right)[(1-u) i-\pi] \\
& s_{d}=\left(1-m_{d}\right) i-\pi
\end{aligned}
$$


cent per year, receives a 10 percent investment tax credit, and is allowed depreciation deductions at 15 percent per year. "Structures" depreciate at an annual rate of 3 percent, receive no investment tax credit, but are allowed accelerated depreciation deductions at 6 percent per year. Finally, "intangibles" (e.g. advertising or R\&D) are assumed to depreciate at 10 percent, receive no tax credit, but may be written off immediately. These asset characteristics are summarized in Table 2. Tax rate estimates will be sensitive to these assumed parameters, but they do represent plausible examples of real asset characteristics. Notice that equipment and intangibles are technologically identical (have the same depreciation rate). We can thus attribute their different results purely to differences in tax treatment.

It remains to specify the interest rate. Hall chooses as his starting point an assumed real after-corporate-tax interest rate of .04 . In the absence of inflation, this is our $(1-u) i_{0}$, We also consider .02 and .06 as alternative assumed values of $(1-u) i_{0^{*}}$ Whereas Hall takes Modified Fisher's Law (4b) as given, we want to look at the effect of varying this assumption. We take Strict Fisher's Law (4a) as an alternative. In each case we display the results for $(1-u) 1_{0}$ equal to $.02, .04$, and .06 .

\section{TABLE 2}

\section{Parameters for Three Asset Categories}

1

2

3

\section{$\underline{\text { Definition }}$}

$\underline{\text { Parameter Equipment } \text { Structures Intangibles }}$

Effective investment tax credit rate

k

$\delta$

Tax depreciation rate rate

Economic depreciation

$\delta^{\prime}$

.1

.1 .15
0 .06
0

$\infty$ 
As mentioned above, we consider ten percent inflation with (4a), ten percent inflation with ( $4 \mathrm{~b})$, and zero inflation, a rate at which the two versions of Fisher's Law imply the same interest. We thus consider three inflation assumptions, three distinct saver types, three asset types, and three values of (1-u) $i_{0}$. Any single interest-inflation combination can be used in one direction to determine the social return on each investment, $\rho$, or in the other direction to determine the return to each saver, $s$. The values of $\rho$ and $s$ for all of these combinations are displayed in Table 3.

Readers are advised to spend a few minutes absorbing Table 3. Notice, for example, that because intangibles are expensed, this form of investment is effectively untaxed at the corporate level $\left(\rho=s_{c}\right)$. The column of real returns on intangibles just shows the behavior of the real after-corporatetax interest rate under the various assumptions. With Strict Fisher's Law and low values of $(1-u) i_{0}$, this interest rate is negative. The colum of real returns to tax-exempt debt holding savers, $s_{d}$, shows what happens to $i-\pi$ under the various assumptions. With Modified Fisher's Law, the real rate of return to tax-exempt debt holders rises sharply with inflation.

Readers can now construct their own effective tax rates. First, choose a row of Table 3. Second, subtract from any real social rate of return $\rho$, any saver's real return $s$ in that row. Third, decide whether to divide by the former, the latter, or not at all. In the remainder of this paper, we discuss some of the issues to keep in mind during this exercise. 
$-19-$

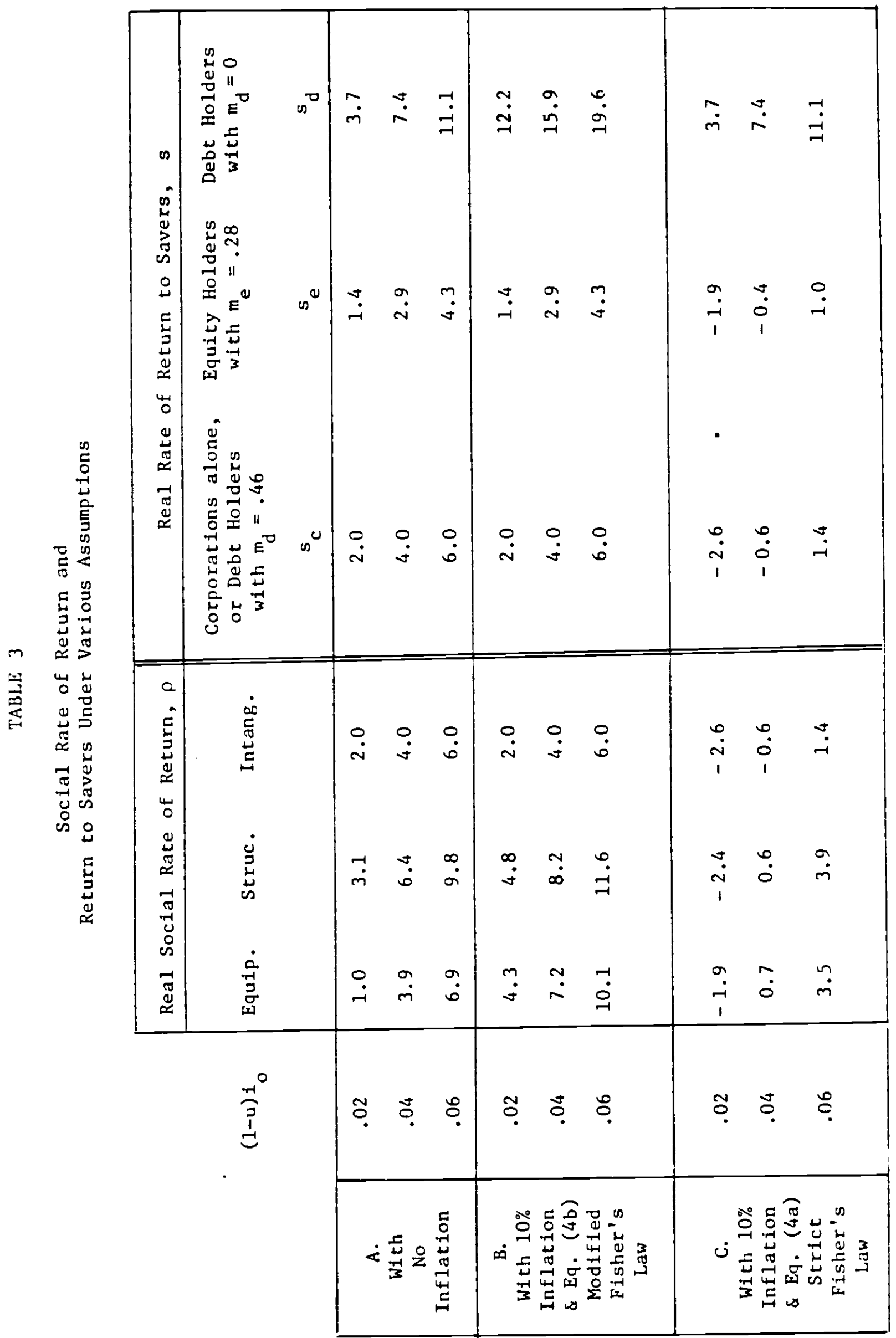




\section{Three Caveats}

\section{III.1. Tax Rates are Sensitive to the Interest Rate}

The first of our three points is very simple, now that the apparatus of Section II is available: effective tax rate estimates depend on the assumed interest rate. Given $\pi$, the interest rate determines $\rho$. Thus each tax rate, such as $t_{c}^{g}, t_{e}^{g}$, or $t_{d}^{g}$, is a function of the interest rate. Different tax estimates will result from different interest rates used as input.

Later, we shall develop the point that tax rates are also sensitive to how inflation affects nominal interest rates. To abstract from that point here, consider the simple case with no inflation. Table 4, Part A, displays the various gross tax rates under these circumstances.

Let us pause to study the numbers in Table 4A. Looking across any row, say for $(1-u) i_{0}=.04$, we see the expected wide range of effective rates applicable to different holders of different types of claims on different forms of real capital. The effective corporate tax rate on intangibles is zero, because this asset receives immediate expensing, which is equivalent to eliminating the tax. The corporation equates $\rho$ on this investment to the after-tax return it can earn on other assets, $(1-u) i$. Since $i$ is the rate of return received by tax-exempt bondholders, their implied effective tax rate is negative: $t_{\mathrm{d}}^{\mathrm{g}}=(\rho-i) / \rho=-u /(1-u)=-85$ percent. The holder of equity, on the other hand, pays a tax of 28 percent (the assumed value of $\left.\mathrm{m}_{\mathrm{e}}\right)$ on $\rho=(1-\mathrm{u}) \mathrm{i}$.

Still for $(1-u) i_{0}=.04$, the effective corporate rate on structures is 37 percent, below the statutory rate of 46 percent. This jifference reflects depreciation allowances in excess of economic depreciation. The percent higher 55 /total tax rate on equity simply reflects the "double taxation" 


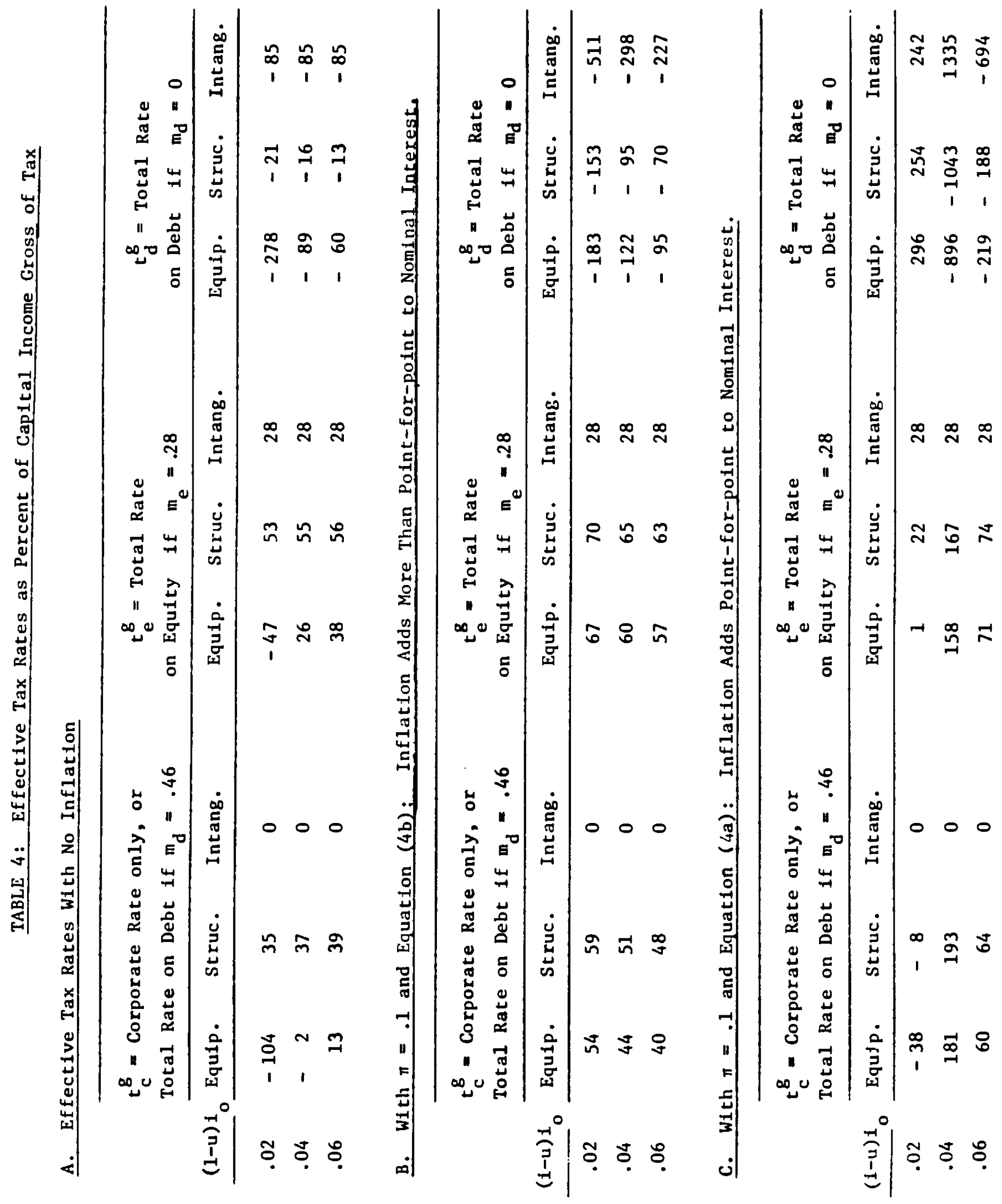


of corporate income. Finally for structures, the rate on debt is -16 percent. This subsidy is less than the subsidy for intangibles because structures do not receive immediate expensing. This asset has a higher marginal social rate of return while the return to debt-holding savers is the same.

The three tax rates for equipment follow a similar pattern. Investment tax credits and accelerated depreciation imply a near zero corporate rate, while the rate on equity is higher and debt is lower.

Now we turn to examination of the columns of Table 4A, that is, to the effect of varying the assumed interest rate. We note immediately that the effective taxes on intangibles are unaffected while those on equipment move rather dramatically. The former result follows from the fact that the various tax rates are simple multiples of $(1-u)$, independent of 1 . Put another way, there are no delayed taxes or benefits with immediate expensing, so the discount rate does not matter.

The behavior of the effective taxes on equipment can be understood by re-examining three aspects of equation (2). First, the return on the investment is indeed taxed at rate $u$. Second, it receives investment tax credit at rate $k$. Third, it receives accelerated depreciation since $\delta^{\prime}>\delta$ (we can ignore historical cost problems here since $\pi$ is zero). When the discount rate $(1-u) i_{0}$ is low, the future depreciation advantages are relatively more important. Together with the investment tax credit, they outweigh the corporate tax, and a net subsidy results. As the discount rate increases, accelerated depreciation becomes less and less important until the corporate tax outweighs the credits and deductions, so a net tax results. The effective tax rates for structures turn out to be less sensitive to 
the interest rates in the range considered here. Because structures do not qualify for the investment credit, the effective corporate tax rate must be at least zero.

The sensitivity to the interest rate remains even when there is inflation. Let us continue to delay the issue of how inflation affects nominal interest rates. For now, just consider the case of equation (4b), where the real after-corporate-tax interest rate $(1-u) i-\pi$ is constant. The nominal interest rate starts with no inflation at $i=i_{0}$, and increases to $i=i_{0}+\pi /(1-u)$ with inflation at rate $\pi$ of 10 percent. Resulting effective tax rate estimates are shown in Table $4 B$.

Again the tax rates with $(1-u) 1_{0}=.04$ reproduce estimates from Hall's paper. Again the tax rates on intangibles are insensitive to this interest rate, except for $t_{\mathrm{d}}^{\mathrm{g}}$. The insensitive tax rates result from the fact that the real after-tax interest rate is constant. For tax-exempt bondholders, however, the real return rises because the equilibrium market interest rate increases by more than the inflation rate. The higher is the inflation rate (relative to the rate of return) the larger is this subsidy.

Tax rates for equipment and structures in Table 4B may appear to be fairly stable, but only because of the range for $1_{0} \cdot$ Hall reports a 44 percent tax rate at $(1-u) i_{0}=.04$, while the table shows a lower rate $(40 \%)$ at .06 and a higher rate $(54 \%)$ at .02 . In fact, as $(1-u) i_{0}$ is reduced further, the tax rate gets even higher. This sensitivity is displayed dramatically in Figure 1, which plots $t_{c}^{8}$ for equipment against the real after-tax interest rate $(1-u) i_{0}=(1-u) i-\pi$ with ten percent inflation. With $(1-u) i_{0}$ between zero and .06 , one obtains tax rates anywhere between 40 percent and 100 percent. 


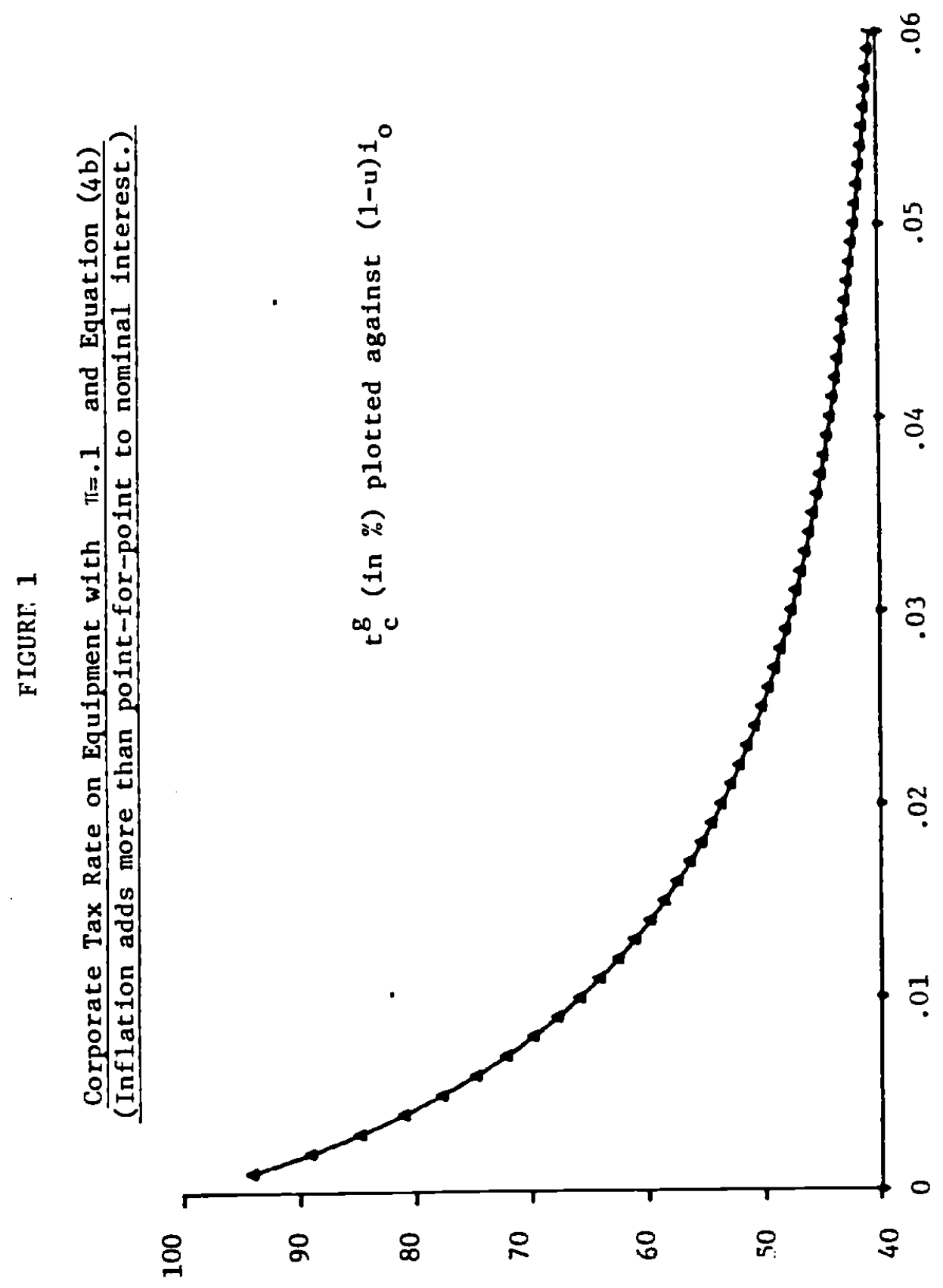




\section{III.2. The Denominator Can Be Zero}

Our second caveat concerns the manner in which a given tax wedge is expressed. Even if we agree on an interest rate (in order to set aside the problems of the previous section), the resulting tax rate estimate might imply that the entire return to investors is financed by government through investment tax credits and accelerated depreciation allowances that outweigh the corporate tax. The required return on the investment, $\rho$, may be zero. In this case the rate of $\operatorname{tax} t^{g}=(\rho-s) / \rho$ is not defined. If the saver obtains a positive rate of return, it is paid entirely by a tax subsidy. While the gross tax rate is undefined, the net tax rate is defined and equals -100 percent. However, there is no insurance against $s$ going to zero either. The real net of tax return of savers has even been negative in riskless terms with inflation. The remaining alternative is merely to report the total wedge $t^{\mathrm{w}}=\rho-s$. This value can be interpreted as a "property tax" rate, the percentage of asset-value paid in tax each year.

To illustrate the relevance of this problem, consider the corporate tax rates $t_{c}^{g}$ on equipment without inflation. These tax rates are reported for selected interest rates on the left side of Table 4A. They are also reproduced in Figure 2 for all interest rates between zero and $(1-u) 1_{0}=.06$. With high interest rates (.06), accelerated depreciation has a low present value, and a small net tax results. At $(1-u) i_{0}=.04$, as reported in $\mathrm{Hall}$, tax credit and depreciation advantages just about balance the tax at rate $u$, with an effective corporate tax rate of nearly zero. With lower interest rates, the depreciation advantage is more important, $\rho$ is always less than $(1-u) 1_{0}$, and $t_{c}^{w}$ (the numerator of $t_{c}^{g}$ ) is always negative. Near $(1-u) 1_{0}=.014$, the subsidy rate can be as high as desired, since $\rho$ approaches zero. With 


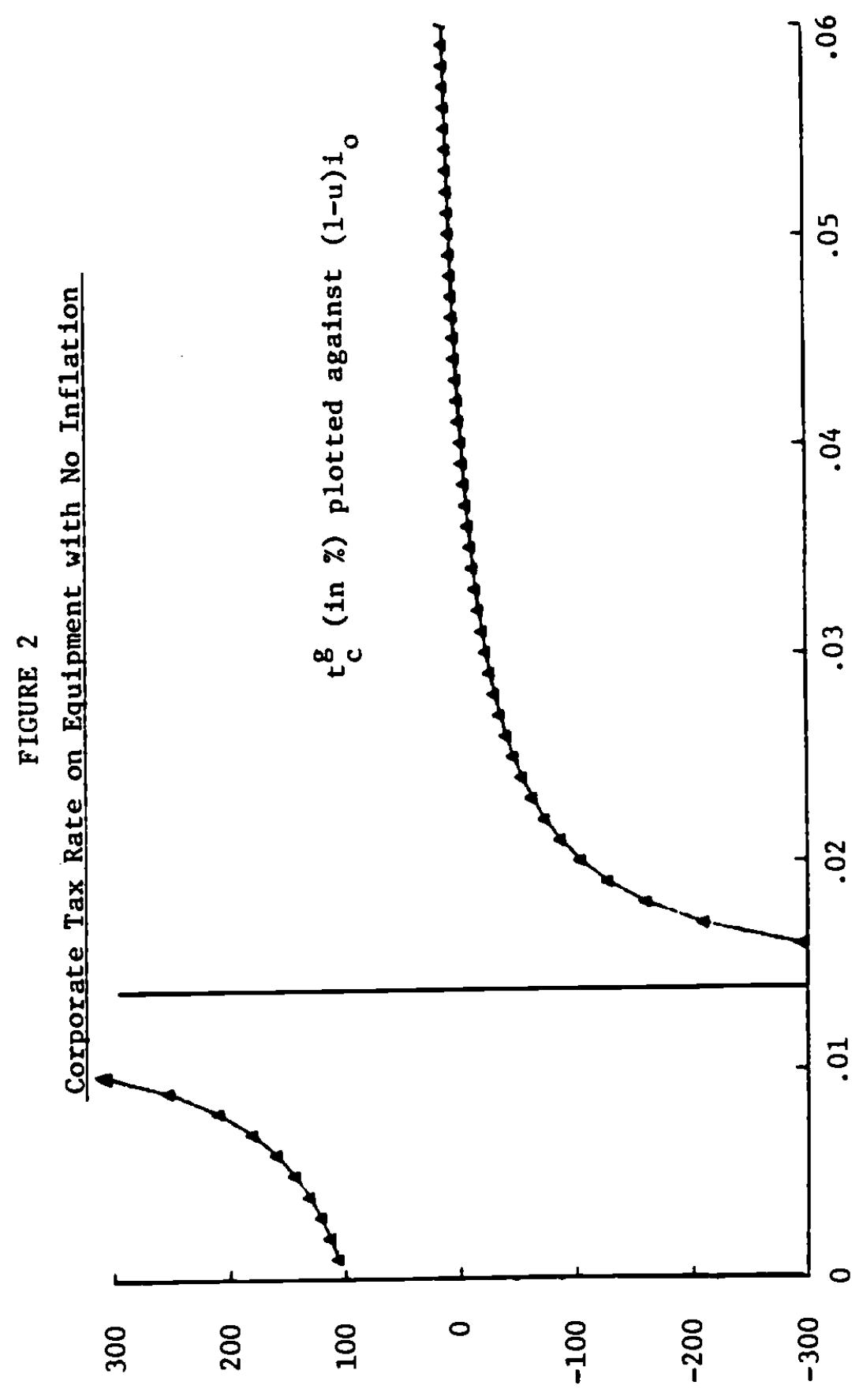


interest rates below .014 , however, $\rho$ in the denominator is also negative, with the anomalous result that $t_{c}^{g}$ is positive. In no sense is there a positive tax rate in this region, since $\rho<(1-u) i_{o}$, yet $t_{c}^{g}$ will be positive.

\section{TABLE 5}

\section{Alternative Expressions for the Effective Corporate Rate}

\section{(Equipment, No Inflation)}

\begin{tabular}{|c|c|c|c|}
\hline$(1-u) i_{0}$ & $t_{c}^{w}=\rho_{-s}$ & $c_{c}^{g}=t_{c}^{w}$ & $\begin{array}{l}n \\
c\end{array}=t_{c}^{w}$ \\
\hline .01 & -1.45 & 322 & -145 \\
\hline .02 & -1.02 & -104 & -51 \\
\hline .04 & -.08 & -2 & 0 \\
\hline .06 & .93 & 13 & 16 \\
\hline .08 & 2.00 & 20 & 25 \\
\hline
\end{tabular}

$t_{c}^{w}$ is a percent of asset-value paid in tax each year. The other tax rates are expressed as a percent of the capital income flow.

Table 5 summarizes the possibilities for this example of the effective corporate tax on equipment with no inflation. The use of $t_{c}^{g}$ is not really acceptable, because the subsidy at .01 appears as $a+322$ percent tax. The net rate $t_{c}^{n}$ seems to make more sense, since the sign is correct 
here. However, Table 3 reveals that $s_{c}$ could also be negative in the denominator of $t^{\mathfrak{n}}$. In such a case, a subsidy would again appear as a positive net tax rate. Furthermore, both gross and net tax rates are subject to misleadingly wide variation when their denominators are close to zero.

These considerations seem to point toward the use of $t^{w}$ alone; we do not need a denominator. This effective tax always has the right sign and is not so sensitive to small changes in the assumption about interest rates. However, the problem of the assumed interest rate does not vanish. The tax wedge $t^{w}$ does become larger as the rate of return increases, even though the rate of tax levels off as seen in Figure 2.

The moral seems to be that analysts should report the underlying components $\rho$ and $s$, as well as summary figures such as tax wedges, gross tax rates, or net tax rates. They should also include a discussion of the sensitivity of these figures to the underlying assumptions. To follow our own advice, we report tax wedges in Table 6 for each asset and inflation scenario. This table has the same format as Table 4.

\section{III.3. The Inflation Assumption Matters}

Fisher's original law predicted that 1 would increase by $\pi$ in a world with no taxes. Since most investment takes place in corporations with tax rate $u$, however, one is tempted to adopt the modified view that 1 should increase by $\pi /(1-u)$, keeping constant the real interest rate after corporate taxes. This is the basis for Hall's assumption.

There are, however, influences which weaken the a priori case for this outcome. First, not all investors have the same marginal rate. If the system is dominated by nonprofit institutions with $m_{d}=0$, then the 


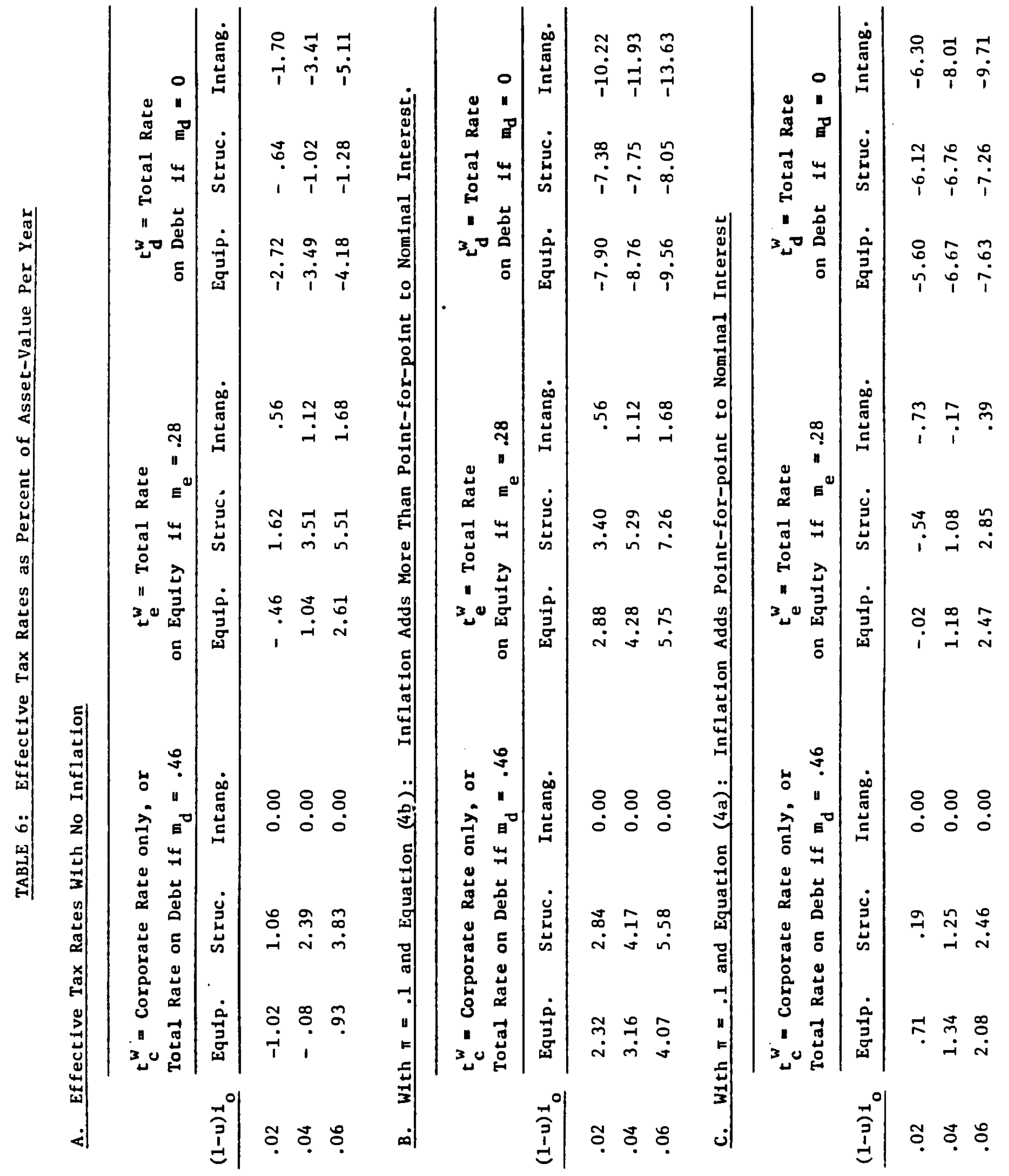


argument behind Fisher's Law would imply that $i$ increase only by $\pi$, to keep their real (nontaxed) interest rate constant. Second, even if all tax rates did equal $u$, historical cost depreciation and taxation of nominal capital gains will tend to reduce the real net return on investments when there is inflation. These features imply that the interest rate would tend to rise by less than $\pi /(1-u)$ with inflation.

Feldstein-Summers (1978) have estimated that inflation adds approximately point-for-point to nominal, interest rates. This is not the result of a simple Fisher's Law without taxes. Rather, it is the result of two countervailing forces within the tax system: taxation of nominal interest at some average rate, call it $m$, tends to raise $i$ by $\pi /(1-m)$, while historical cost depreciation and taxation of nominal capital gains tend to pull the adjustment below this level.

Jorgenson and Sullivan also use empirical work to support their assumption of a constant real after-tax rate of return on corporate investment. This estimated constancy would appear to contradict the results of Feldstein and Summers. The difference can be reconciled by a limitation on arbitrage between bonds and real capital, implicitly invoked by J-S. With such a limitation, real after-tax interest rates could fall with inflation (Feldstein and Summers), while real after-tax rates of return are constant (J-S). In terms of our analysis, the J-S procedure is equivalent to assuming Modified Fisher's Law as far as effective corporate and equity tax rates are concerned. Calculating effective tax rates applicable to bondholders would require a separate model of interest determination.

The choice between Strict and Modified Fisher's Laws does affect tax rate estimates. As is clear from Table 3, the required real social returns on investment, $\rho$, and the real net return to savers, $s$, depend critically on how inflation affects the nominal interest rate. 
Consider first the Strict Fisher's Law of equation (4a). With ten percent inflation, Table 3 shows low and even negative required real rates of return on investment. If the demand for capital is inversely related to this required return, (4a) Implies an increased capital stock. At the same time, Table 3 shows lower real rewards to saving under Strict Fisher's Law. If the supply of savings is positively related to its real net return, this would imply a decreased capital stock. The nominal interest rate would have to increase by more than $\pi$ to encourage savers to supply enough capital to meet investment demand. The figures in Table 3 by themselves cannot represent an equilibrium.

Now consider Modified Fisher's Law (4b). The large nominal interest increase associated with inflation implies a higher required real return on two of the three illustrative asset categories of Table 3. The higher required $\rho$ would suggest lower incentives to invest. At the same time, however, most savers are receiving higher real returns with inflation. These Table 3 figures cannot be in equilibrium, either. Only if interest rates increased by something less than $\pi /(1-u)$ would savers' desired wealth match the producers' desired capital.

Thus equations (4a) and (4b) represent two logical possibilities for an unknown relationship: the truth is likely to lie somewhere in between. If the assumption of Hall and $\mathrm{J}-\mathrm{S}$ is correct, then gross tax rates with $T=.1$ will look like Part B of Table 4. If, on the other hand, estimates from Feldstein-Summers (1978) are correct, gross tax rates with $\pi=.1$ will look like Part $C$ of Table 4.

Table $4 \mathrm{C}$ illustrates some of the difficulties to which effective tax rates are subject. The corporate rates on equipment and structures are nega- 
tive when $(1-u) i_{0}$ is .02 . As can be confirmed by reference to Table 3 , these are cases of negative social rates of return. Since the return received

by a 46 percent bondholder is even more negative, these negative numbers in $4 \mathrm{C}$ reflect a positive tax. At higher values of (1-u) $i_{0}$, relatively large positive corporate tax rates are shown. If we compare the tax rates here to those with no inflation in $4 \mathrm{~A}$, we might draw the conclusion that inflation effects a disincentive to invest. Again, a glance at the social rates of return in Table 3 will confirm that $\rho$ is sharply lower with inflation and Strict Fisher's Law. This can only be the result of increased investment, which pushes down the marginal rate of return. Such an outcome is to be expected, since inflation lowers real corporate borrowing costs under this assumption. The relative increase in effective tax rates is simply the result of much smaller denominators in the gross tax rate formula.

One last anomaly will complete the catalog of illustrations. Look at intangibles in the bottom right-hand corner of Table 4. We now have outrageous $t_{d}^{g}$ tax rates between -694 percent and +1335 percent. Table 3 or 6 reveals that the wedge $\left(\rho-s_{d}\right)$ is in fact negative for all three values of $(1-u) i_{0}$. For .02 and .04 , however, this subsidy is larger than the saver's return, and $\rho$ is negative in the denominator. We thus have negative numbers in Table 4 reflecting positive taxes, and positive numbers in the table reflecting negative taxes.

\section{Concluding Remarks}

Table 4 exemplifies three separate conclusions. Tax rates are sensitive to the interest rate $(.02, .04, .06)$, tax rates are sensitive to the assumed effect of inflation on nominal interest (part $B$ vs. part C), and tax rates are not best expressed as a percent of gross capital income $\rho$. 
Beyond the three major caveats discussed in this paper, there exist other more subtle problems. We are forced by the limits of this paper to abstract from them, as have other studies. However, we might take a few paragraphs to outline these problems for the sequel.

Different effective tax rates are useful for different purposes. First, one may want an average tax rate or "flow of funds" rate to capture income effects, as described in our introduction. Second, there are different types of marginal tax rates. Capital income can increase because of higher rates of return or because of more investment. Since only the latter induces an investment credit, for example, the effect on taxes is not the same. Feldstein and Summers (1979) are not interested in the additional tax associated with another unit of investment. Instead, they seek to measure the effects of inflation on taxes. They need to specify the effect of inflation on nominal interest rates as well as the effect of nominal interest rates on real taxes paid.

Third, even if we agreed on marginal tax rates for additional investment, we might want an effective corporate rate, an effective personal rate, or the total effective wedge between the marginal product and the saver's rate of time preference. Consider for a moment the use of each such rate. The assumptions of our investment model rely heavily on a single market interest rate. Given this baseline for all corporate investment, the "effective corporate tax rates" can be used to measure the misallocations of capital among assets in the corporate sector. They cannot be used, for example, to capture misallocations between the corporate and noncorporate sectors. Given the same market interest rate as a baseline, different savers earn different net of tax returns. Thus "personal effective tax rates" can be 
used to measure a "misallocation" of savings in the personal sector: not all marginal rates of time preference are identical. Finally, only the total effective wedge between the marginal social rate of return $\rho$ (averaged over different assets), and the marginal rate of time preference s (averaged over different savers), can be used to measure the misallocation of consumption between present and future periods, as caused by capital income taxation.

Analyses of allocative and distributive effects are hampered by the questionable consistency of the tax rates estimated with the assumption of overall equilibrium in capital markets. $\underline{9}$ Condition (2) expresses the requirement that the corporation should have maximized its profits in equilibrium. There can then be no potential for the corporation to gain by arbitrage between bonds and real capital. There are, however, other conditions one might wish to hold. For example, it might be required that profits of noncorporate investors from the same sort of arbitrage be eliminated. Equilibrium would then call for the analogue of condition (2), but with the proprietor's marginal rate $m$ replacing the corporate marginal rate u. But (2) cannot hold for both $m$ and $u$. (unless they are equal).

For the model to tell a consistent story about the effect of taxes, it is necessary to find a way for corporations, individuals, and taxexempt institutions to be in equilibrium simultaneously. There are two basic ways such a reconciliation might be accomplished. The first is to adopt assumptions that constrain the agents of the model. For example, it seems natural to impose borrowing limits on individuals, and to limit negative positions in (short sales of) real capital. One 
might simultaneously assume that corporate and noncorporate technologies are distinct, so that investment opportunities available to corporations are not available to other firms.

By a careful combination of such restrictions, a consistent model should be feasible. At this stage, the point to emphasize is that the particular constraints imposed are likely to have a significant bearing on the distorting consequences attributable to taxes. Take as an example the constraint that tax-exempt savings by individuals are subject to fixed ceilings. This assumption is likely to eliminate any allocative effects of the sort of subsidy to zero bracket bondholders that is apparent from Table 4 or Table 6.

The method of imposing constraints is likely to imply extreme specialization of portfolios. Individuals will hold only stock or bonds, for example, not both. The rates of return in the analysis above are treated as certain, and hence no one would hold assets generating different yields. Actual assets, however, are risky. Thus a second approach to resolving the problem of inconsistency is to attempt an explicit treatment of risk.

This undertaking would clearly be difficult, but it is important to explore. The effect of taxing the return to saving may be quite different from the effects of taxing risk premia. As shown in Gordon (1981), and as estimated in Fullerton-Gordon (1981), a tax on risk premia may constitute a simple risk sharing by government, with no distorting effect at all.

Pending modelling advances along the lines described here, we would urge those who construct and use effective tax rates to exercise appropriate caution. 


\section{FOOTNOTES}

1. By the real rate of return $\rho$ we mean the internal rate of return of the project's real cash flow, gross of taxes and subsidies. Because we confine our attention to simple cases, this rate is always well defined.

2. Note we have assumed that the corporation will actually manage to use its investment credit and that it will benefit from the subsequent depreciation allowances. This assumption is far from innocuous because the actual income tax is nonlinear. This nonlinearity is obvious for the case of most individuals, but also holds for corporations risking low or negative taxable income. We have also assumed that depreciation allowances are based on the historical cost of the asset gross of the investment credit. Finally, note that the cash flow to an individual asset owner with marginal tax rate $m$ is obtained by substituting $m$ for $u$ in these expressions.

3. One way of modelling the imperfect substitutability of debt and real capital is to regard the corporation as subject to constraints on this arbitrage, e.g., the outstanding debt cannot exceed some fraction of the value of real assets owned. In this case the relationship (1) will not generally hold for firms where the constraint binds. Other relationships must then determine c/q. See, for example, King (1977). However, the assumption (if only implicit) of unconstrained debt-real capital arbitrage is frequently encountered.

4. Stiglitz [1980] has emphasized that if we really did the analysis "right", 
$\pi$ and $i$ would be simultaneously determined as endogenous variables.

5. To our knowledge the first published appearance of Modified Fisher's Law was in Feldstein (1976).

6. If we use Modified Fisher's Law (4b) to eliminate the current interest rate from equilibrium conditions (2) and (3), we obtain

$$
\frac{c}{q}=\frac{\delta+(1-u) i_{0}}{(1-u)}\left[1-k-\frac{u \delta^{\prime}}{\delta^{\prime}+(1-u) i_{0}+\pi}\right] \text {, }
$$

and

$$
\frac{c}{q}=\frac{\delta+(1-u) i_{0}}{(1-u)}(1-k-u z)
$$

Equation (2b) is equivalent to Hall's crucial equation, except for notational differences. Hall's $d$ and $d$ ' correspond to our $\delta$ and $\delta^{\prime}$, and his taxable proportion of capital gains, $g$, is set to zero. Hall's "real after-tax interest rate," $r$ (assumed constant) is what we have called $(1-u) i_{0}$. Equation $(3 b)$ is the basic equilibrium condition of Jorgenson-Sullivan, with their "rate of return," $r$ (assumed constant) equal to our $i_{0}$.

7. There is a question of consistency or existence of equilibrium if the same taxpayer were to earn different after-tax rates of return on different assets. The concluding section of this paper touches on possible resolutions of this problem.

8. See Bailey (1969) for more discussion on this point.

9. For analyses stressing this problem, see Bradford $(1980,1981)$. 


\section{REFERENCES}

Bailey, Martin J. (1969), "Capital Prices and Income Taxation," in Arnold C. Harberger and Martin J. Bailey (eds.) The Taxation of Income from Capital, the Brookings Institution, Washington, D. C.

Bradford, David F. (1980), "The Economics of Tax Policy Toward Savings," in George von Furstenberg (ed.), The Government and Capital Formation, Ballinger, Cambridge, pp. 11-71.

Bradford, David F. (1981), "Issues in the Design of Savings and Investment Incentives," in Charles R. Hulten (ed.), Depreciation, Inflation, and the Taxation of Income from Capital, The Urban Institute, Washington, D. C. (forthcoming).

Feldstein, Martin (1976), "Inflation, Income Taxes, and the Rate of Interest: A Theoretical Analysis," American Economic Review, 66, December, pp. 809820 .

Feldstein, Martin (1980), "Tax Rules and the Mismanagement of Monetary Policy," American Economic Review, 70, May, pp. 182-186.

Feldstein, Martin, and Lawrence Summers (1978), "Inflation, Tax Rules, and the Long-Term Interest Rate," Brookings Papers on Economic Activity, 1 , pp. 61-109.

Feldstein, Martin, and Lawrence Summers (1979), "Inflation and the Taxation of Capital Income in the Corporate Sector," National Tax Journal, 32, December, pp. 445-470.

Fraumeni, Barbara M. and Dale W. Jorgenson (1980), "The Role of Capital in U. S. Economic Growth, 1948-1976," in George von Furstenberg (ed.), Capital, Efficiency and Growth, Ballinger, Cambridge, pp. 9-250.

Fullerton, Don, and Roger H. Gordon (1981), "A Re-examtnation of Tax Distortions in General Equilibrium Models," forthcoming in an NBER conference volume on tax simulations.

Fullerton, Don, A. Thomas King, John B. Shoven, and John Whalley (1981), "Corporate Tax Integration in the United States: A General Equilibrium Approach", American Economic Review, forthcoming.

Gordon, Roger H. (1981), "Taxation of Corporate Capital Income: Tax Revenues vs. Tax Distortions," mimeo, Bell Labs, Murray Hill, N. J.

Gravelle, Jane G. (1981), "The Social Cost of Non-neutral Taxation: Estimates for Non-Residential Capital," in Charles R. Hulten (ed.), Depreciation, Inflation, and the Taxation of Income from Capital, The Urban Institute, Washington, D. C., (forthcoming). 
Hall, Robert E. (1981), "Tax Treatment of Depreciation, Capital Gains and Interest in an Inflationary Economy," in Charles R. Hulten (ed.), Depreciation, Inflation, and the Taxation of Income from Capital, The Urban Institute, Washington, D. C., (forthcoming).

Hall, Robert E., anj Dale W. Jorgenson (1967), "Tax Policy and Investment Behavior," American Economic Review, 57, June, pp. 391-414.

Harberger, Arnold C. (1966), "Efficiency Effects of Taxes on Income from Capital," in M. Krzyzaniak (ed.) Effects of Corporation Income Tax, Wayne State University Press, Detroit.

Hulten, Charles R., and Frank C. Wykoff (1981), "The Measurement of Economic Depreciation," in Charles R. Hulten (ed.) Depreciation, Inflation, and Taxation of Income from Capital, The Urban Institute, Washington, D. C. (forthcoming).

Jorgenson, Dale W., and Martin A. Sullivan (1981), "Inflation and Capital Recovery in the United States," in Charles R. Hulten (ed.) Depreciation, Inflation, and the Taxation of Income from Capital, The Urban Institute, Washington, D. C., (forthcoming).

King, Mervyn A. (1977), Public Policy and the Corporation, Chapman and Hall, London.

Meade, James E. (1978), The Structure and Reform of Direct Taxation: Report of a Comittee Chaired by Professor J. E. Meade, Allen and Unwin for the Institute for Fiscal Studies, London.

Shoven, John B. (1976), "Incidence and Efficiency Effects of Taxes on Income from Capital," Journal of Political Economy, 84, December, pp. 1261-1283.

Stiglitz, Joseph E. (1980), "On the Almost Neutrality of Inflation: Notes on Taxation and the Welfare Costs of Inflation," NBER Working Paper \#499, Cambridge, Mass. 